\title{
MODM-MCDM Approach to Partner Selection in Auto Industry A Case Study on Mazda of Iran
}

\author{
Kamran Shahanaghi \\ Professor Assistant, Department of Industrial Engineering \\ Iran University of Science and Technology Hengam St. Narmak, Tehran, Iran \\ Tel: 98-21-7724-0135 E-mail: shahanaghi@iust.ac.ir \\ Hossein Yavarian (Corresponding author) \\ Faculty of Industrial Engineering, Iran University of Science and Industry \\ Hengam St. Narmak, Tehran, Iran \\ Tel: 98-912-554-7637 E-mail: h_yavarian@ind.iust.ac.ir
}

\begin{abstract}
Successful business alliances are a critical strategic component in many industries especially Auto Industry, but too many strategic alliances fail to meet their partners' objectives. Many failures result from ill-conceived overall alliance strategies and firm partner selection. In particular, the well-informed and strategically driven selection of alliance partners is a core element in building successful alliances.

The decision-making process associated with selecting an alliance partner is complex and challenging. When managers have access to relevant information and are not under time constraints, they can use a rational, analytical process to evaluate strategic fit among alternatives. Since there was insufficient attention to partner selection in literature review of Auto industry, and there is a strong need for auto firms in this area, the current work aims to address this gap in Auto industry, using multi objective decision making method and then a case study and quantitative evidence from Mazda Company (Iran) are provided.
\end{abstract}

Keywords: MODM, MCDM, Decision making, Strategic alliance, Partner selection

\section{Introduction}

With the increasing emphasis on globalization, strategic alliances have become a highly popular strategy for entry into international markets. The general intent of strategic alliances is to establish and maintain a long-term cooperative relationship in order to compete more effectively with firms outside the relationship. A number of strategic alliances fail; as such, a critical factor in alliances, partner selection, requires more research attention. The decision-making process associated with selecting an alliance partner is complex and challenging, especially when one considers the high rate of alliance failure. When managers have access to all relevant information and are not under time constraints, then they can use a rational, analytical process to evaluate strategic fit among alternatives. On the other hand, in order to provide good products, mandatory industrial standards should be observed by companies. Therefore, a significant gap remains in existing research addressing the following questions:

How to choose partner(s) considering multi objectives comes from mandatory standards and managerial principals?

What are key strategic factors of partner selection in Auto industry?

This research aims to address these gaps by providing an integrated Multi Objective Decision Making (MODM) and Multi Criteria Decision Making (MCDM) method to design the best model for partner selection in Auto Industry. The current work has significant implications for theory and practice by providing a case study and evidences from BAHMAN holding Group (Mazda of Iran).

The rest of this paper is organized as follows. The next section reviews the literature relating to strategic motives and partner selection criteria. The second section sets out the models of the study. The case study of BAHMAN GROUP (Mazda of Iran) is in the third section and conclusions are provided in the last section. 


\subsection{Strategic Alliance and Partner Selection Criteria}

The international business literature has already acknowledged a number of positive outcomes for companies actively engaged in strategic alliances, such as higher return on equity, better return on investment, and higher success rates. According to definition, a strategic alliance involves at least two partner firms that:

a) Remain legally independent after the alliance is formed;

b) Share benefits and managerial control over the performance of assigned tasks; and

c) Make continuing contributions in one or more strategic areas, such as technology or products.

Strategic alliances continue to grow in popularity and recent years have witnessed a burgeoning interest in functions and advantages of strategic alliance formation. In the early 1950s, in one of the first attempts to specify a set of selection criteria for choosing channel members, Brendel (1951) developed a list of 20 key questions for industrial firms to ask of their prospective channel members. Since then, many scholars try to synthesize what kind of criteria that can be used in strategic partner selection, such as Li Dong et all (2006) with 20 factors and motives for partner selection in Chinese firms, Overby(2007) argued that firms benefit from allying with weak partner at certain times. He show that appropriate partner selection criteria are dynamic and may involve allying with weak partners in the initial exploratory stage, with weak and/or strong partners in the development stage and with strong partners in the maturity stage. Bierly \& Gallagher(2007) has articulated how a multiple level of analysis approach to understanding strategic fit and trust, coupled with a new appreciation for time as embodied in the concept of strategic expediency, can better inform the alliance partner selection process. Holmberg \& Cummings (2009) proposed a new dynamic partner selection tool to evaluate target industries and specific firms, which is applicable to multiple alliance and industry contexts.

\subsection{Methods and Models of Partner Selection}

In response to the growth of partner selection both qualitative and quantitative methods have been used. Mikhailov (2002) used fuzzy approach to partnership selection, Jarimo (2006) developed mixed integer linear programming model to support the configuration of Virtual Organizations. A decision support system and related software designed by Marxt \&Fahrni (2006) for strategic venture partner selection in production systems, Yang, Kim, Nam \& Min (2007) proposed Analytical Hierarchy Process(AHP), using ten factors in three main categories (Risk, expectation and Environment) for business process outsourcing. A quantitative research for partner selection in R\&D alliances done by Eden (2007) on the basis of hypothesis and statistical calculations and finally Doherty (2009) introduced a qualitative method to identify the key factors influencing partner selection for international retail franchisors.

\section{Methodology}

This study used a survey quantitative research that allowed the researchers to integrate training management literature, in-depth interviews. Delphi method was adopted to collect data from a series of expert panels that consist of managers or an appropriate person for the same tasks from Auto industry. The use of such methods may gather accurate and less biased data .This study was conducted at BAHMAN GROUP (MAZDA), Iran. At the initial stage of this study, in-depth interviews were conducted involving seven experienced employees, namely New Business Development manager, R\&D executive and five experienced experts from related departments.

This study intends to use this industry because of intense alliance formation in the industry. A consensus process was performed by repeated interrogations through questionnaires of experts group individually; each interrogation was accompanied by providing information of proceeding round of replies. They were encouraged reexamining and changing their previous reply regarding to others reply.

\section{MODM-MCDM approach to partner selection in Auto industry}

The method we use in this study follows three steps. Model of project is shown in figure (1).

The first step is to define a target for partner selection which is the most important section of the whole project. Target definition consists of three major subsidiaries:

a) Defining needed product with detail technical specifications, price and class.

b) Defining what our organization possess (properties \& knowledge).

c) Defining the other limitations (annual production volume and partnership structure)

According to resource view of strategic alliance, resource types (property-Based and knowledge-Based resources), affects structural preferences. For instance a partner firm will prefer unilateral contract-based alliances if both partner firms' primary resources regarding the prospective alliance are property-based. 
Second step is searching for potential alternatives of partnership. In third step, we are going to define key factors influencing partner selection in auto industry. Many studies took place to find out key factors of partner selection, some of them were indicated in literature review. This article tries to develop critical success factors of partner selection in auto industry, on the basis of previous studies, expert's opinions and personal ideas.

According to literature review and expert's opinions, basic criteria for partner selection in Auto industries are capability of both $\mathrm{CBU}(\mathrm{Completely} \mathrm{Built} \mathrm{Up} \mathrm{Unit)} \mathrm{and} \mathrm{CKD}$ (completely knocked down unit) production, gross profit, access to facilities and reach to strategic goals. Also we have to consider some legal limitations such as fuel consumption, product specifications and partner's technical abilities.

Since top management wants to optimize several goals at the same time, we have to choose Multi Objective Decision Making process. On the other hand the problem involves Multi Criteria Decision Making because the best choice(s) should be selected among alternatives. On the whole the problem solving process is complicated. By integrating MODM and MCDM we develop a new model to overcome the problem.

\section{Case Study}

To verify the model, theoretical concept should be test in actual environment. In order to illustrate and motivate the method we have developed the MODM_MCDM Model in BAHMAN Group's decision making process. The results of implementation are as bellow:

\subsection{Set a Target for Partnership}

As it was mentioned before this step includes three levels: Defining needed product with detail technical specifications and price, Defining what we have (properties \& knowledge) and Defining other limitations.

Defining needed product with detail technical specifications and price: According to market analysis, there is a significant gap in relevant market map for van products in Iran's market. By reference to market map and competitive analysis, the needed product will be define. In table (1) needed technical specifications and other limitation for partner selection are shown.

Defining what we have (properties \& knowledge): Since Bahman Group(BG) has a shining background in the field of van production, a good opportunity exists in this section for cooperation with foreign companies in terms of bilateral contract-based cooperation.

Defining other limitations:

a) Assembly capacity for the factory is 10000 sets per year.

b) Total demand for product exceeds 15000 sets per year.

c) The average Technical specification for each van should be 38 at least.

d) The average fuel consumption for each van should be less than 6.88 liters per 100 kilometer.

\subsection{Searching for Potential Alternatives}

According to searches potential alternatives are FAW, GD, Siba and ZX.

\subsection{Applying MODM-MCDM Model}

Management wants to maximize gross profit for each unit sold (both CKD and CBU), usage of partner's technical abilities and reach to strategic goals of partnership. Goal programming was applied to formulate and solve the problem. According to interviews and analysis of questionnaires (dual comparisons), weights of the above mentioned goals are $0.68,0.23$ and 0.09 respectively. To use linear programming, these goals should change to one. We use additional technique in order to concise goals and change them to one goal. (See table 3and 4).

Table (1) shows needed technical specifications and other limitation for partner selection. Also linear formulation is depicted in table (2).

\section{Results and Conclusion}

Finding the partner selection criteria and developing an appropriate partners selection model are the most important issues before a strategic alliance is formed. It is imperative for decision makers to devise, identify and recognize effective partner selection criteria prior to forming a joint service pact. In order to design a more effective decision-making process, this study applies MODM_MCDM approach to find the best solution for partner selection in Auto industry. 
Since top management wants to optimize several goals at the same time, we have to choose Multi Objective Decision Making process. On the other hand the problem involves Multi Criteria Decision Making because the best choice(s) should be selected among alternatives. On the whole the problem solving process was complicated. By integrating MODM and MCDM we develop a new model to overcome the problem. In order to illustrate and motivate the method we have developed the MODA_MCDM Model in BAHMAN Group's decision making process.

Results of applying the model shows that 1400 CBU units should purchase from alternative 2(FAW company), 3600 CBU units should buy from alternative 4(Siba company) and 10000 CKD units should purchase from alternative 2(FAW company). Total Objective value found 14232 which derived from three functional goals (maximum gross profit, maximum reach to strategic goals of partnership and maximum usage of partner's technical abilities). Table (5) shows Global optimal solution which was generated by Lingo software.

Having reach to such information, managers and decision makers are able to follow the process of decision making systematically. It is noticeable that the model we provided in this article, has been applied in BG Company and the results were desirable and approved by New Business Development manager and it can be applicable for the other situations. (See appendix A).

\section{Future Researches}

The following items suggested for future researches:

a) The problem of partner selection considered for choosing two or more firms cooperating in parallel with the other organization to supply a specific product.

b) New alliance structures models provide considering the conditions of risk, resource and the other limitations simultaneously.

c) The analysis of partner selection under the conditions of uncertainty.

d) Using the other decision making models for partner selection in auto industry to figure out what is the best model.

\section{References}

Bierly III P.E., \& Gallagher S. (2007). Explaining Alliance Partner Selection: Fit, Trust and Strategic Expediency. Long Range Planning, 40, 134-153.

Brendel, L. H. (1951). Where to find and how to choose your industrial distributors. Sales Management, 15, $128-132$.

Das T.K., \& Teng B.S. (2000). A resource-Based Theory of strategic alliances. Journal of Management, (26)1, 31-61.

Das T.K., \& Teng B.S. (2001), A risk perception model of alliance structuring. Journal of International Management, 7, 1-29.

Dong Li \& Glaister Keith W. (2006). Motives and partner selection criteria in international strategic alliances: Perspectives of Chinese firms. International Business Review, 15, 577-600.

Doherty A.M. (2009). Market and partner selection process in international retail franchising. Journal of Business Research, 62, 528-534.

Eden L. (2007). Friends, acquaintances or strangers? Partner selection in R\&D Alliances, Texas A\&M University, Bush School working paper.

Hacklin F., Marxt C., \& Fahrni F. (2006). Strategic venture partner selection for collaborative innovation in production systems: A Decision support System-based approach. International journal of production economics, 104, 100-112.

Hitt M.A., Dacin M. T., Levitas E., Arregle J.L., \& Borza A. Partner selection in emerging and developed market context: Resource-Based and organizational learning perspectives. Lowry Mays college and Graduate School of Business, Texas A\&M University.

Holmberg S.R., \& Cummings J.L. (2009). Building Successful Strategic Alliances. Long Range Planning, 42, 164-193.

Jarimo T. (2006). Partner selection and utility sharing in collaborative networks, Licentiate's Thesis. Helsinki University of Technology. Department of Engineering Physics and Mathematics. 
Löber G., \& Staat M. (2010). Integrating categorical variables in Data Envelopment Analysis models: A simple solution technique. European Journal of Operational Research, 202, 810-818.

Mikhaliov L. (2002). Fuzzy analytical approach to partner selection in formation of virtual enterprises. Omega (The International Journal of Management Science), 30, 393-401.

Madlener R., Antunes C.H., \& Dias L.C. (2009). Assessing the performance of biogas plants with multi-criteria and data envelopment analysis. European Journal of Operational Research, 197, 1084-1094.

Overby M.L. (2007). Partner Selection Criteria in Strategic Alliances: When to Ally with Weak Partners. Danish Research Unit for Industrial Dynamics, ISBN 87-7873-171-2.

Todeva E., \& Knoke D. (2005). Strategic alliances and models of collaboration. Management Decision, (43), 123-148.

Wu W.Y, Shih H.A \& Chan H.C. (2009). The analytic network process for partner selection criteria in strategic alliances. Expert Systems with Applications, 36, 4646-4653.

Yang D.H, Kim S., Nam C., \& Min J.W. (2007). Developing a decision model for business process outsourcing. Computers and operation research, 34, 3769-3778.

Table 1. Needed technical specifications and other limitation for partner selection

\begin{tabular}{|c|c|c|c|c|}
\hline \multirow{2}{*}{ Criteria } & \multicolumn{4}{|c|}{ Alternatives } \\
\cline { 2 - 5 } & GD & FAW & ZX & Siba \\
\hline CBU production & 7000 & 6000 & 10000 & 12000 \\
\hline CKD production & 10000 & 12000 & - & - \\
\hline Gross profit for each CBU & 1000 & 1100 & 900 & 950 \\
\hline Gross profit for each CKD & 800 & 950 & - & - \\
\hline Reach to Strategic Goals & 19 & 23 & 15 & 15 \\
\hline Fuel consumption per 100 kilometer & 7.1 & 7 & 6.6 & 6.5 \\
\hline Product Technical Specifications & 42 & 45 & 30 & 35 \\
\hline Partner's Technical Score & 51.2 & 46.5 & 38.8 & 43.1 \\
\hline
\end{tabular}

Table 2. Linear formulation

$\max z=w i * \sum_{j=1}^{n} A t j *(x j+y j)$

1) $\sum_{j=1}^{n} A t j *(x j+y j) \geq B$

2) $x j \leq A t j, j=1,2, \ldots, n, t=1$

3) $y j \leq A t j, j=1,2, \ldots, n, t=2$

4) $\sum_{j=1}^{4} y j \leq C$

5) $\sum_{j=1}^{4} x j \geq E$

6) $\sum_{j=1}^{4} x j+y j=D$

7) $\sum_{j=1}^{4} A t j *(x j+y j) \leq F$
$\mathrm{Wi}=$ objective weights

Atj $=$ scores number $\mathrm{t}$ for alternative $\mathrm{j}$

$\mathrm{Xj}=$ total number of $\mathrm{CBU}$ products that alternative $\mathrm{j}$ will provide

$\mathrm{Yj}=$ total number of $\mathrm{CKD}$ products that alternative $\mathrm{j}$ will provide

$\mathrm{B}=$ Technical specification standards

$\mathrm{C}=$ capacity of assembly line in our factory

$\mathrm{D}=$ total demand for product

$\mathrm{E}=\mathrm{D}-\mathrm{C}$

$\mathrm{F}=$ fuel consumption extreme 
Table 3. Linear formulation for case study (parametric)

$$
\begin{aligned}
& \max z=w i * \sum_{j=1}^{n} A t j *(x j+y j) \\
& \text { 1) } \sum_{j=1}^{4} A t j *(x j+y j) \geq 570000, t=5 \\
& \text { 2) } x j \leq A t j, j=1,2, \ldots, n, t=1 \\
& \text { 3) } y j \leq A t j, j=1,2, \ldots, n, t=2 \\
& \text { 4) } \sum_{j=1}^{4} y j \leq 10000 \\
& \text { 5) } \sum_{j=1}^{4} x j \geq 5000 \\
& \text { 6) } \sum_{j=1}^{4} x j+y j=15000 \\
& \text { 7) } \sum_{j=1}^{4} A t j *(x j+y j) \leq 103200, t=6
\end{aligned}
$$

1) Technical limitation

\begin{tabular}{|c|c|}
\hline $\begin{array}{l}\max = \\
0.68 *(0.9090 * x 1+1 * x 2+0.8181 * x 3+0.8636 * x 4+0.8421 * y 1+1 \\
* y 2) \\
+0.23 *(0.8260 *(x 1+y 1)+1 *(x 2+y 2)+0.6521 * x 3+0.6521 * x 4) \\
+0.09 *(1 *(x 1+y 1)+0.9082 *(x 2+y 2)+0.7578 * x 3+0.8417 * x 4)\end{array}$ & $\begin{array}{l}\text { Additive linear programming for objective } \\
\text { functions }\end{array}$ \\
\hline 1) $42 *(x 1+y 1)+45 *(x 2+y 2)+30 * x 3+35 * x 4>=570000$ & 1) Technical limitation \\
\hline 2) $\mathrm{x} 1<=7000 ; \mathrm{x} 2<=6000 ; \mathrm{x} 3<=10000 ; \mathrm{x} 4<=12000$; & 2) Limitation for providing CBU products \\
\hline 3) y $1<=10000 ; y 2<=12000$; & 3) Limitation for providing CKD products \\
\hline 4) $7.1 *(x 1+y 1)+7 *(x 2+y 2)+6.6 * x 3+6.5 * x 4<=103200$; & 4) Limitation for fuel consumption \\
\hline 5) $x 1+x 2+x 3+x 4>=5000$; & 5) Extra limitation in order to fulfill demand \\
\hline 6) $\mathrm{y} 1+\mathrm{y} 2<=10000$ & 6) Limitation for Assembly line Capacity \\
\hline 7) $x 1+x 2+x 3+x 4+y 1+y 2=15000$ & 7) Demand Limitation \\
\hline
\end{tabular}

2) Limitation for providing CBU products

3) Limitation for providing CKD products

4) Limitation for fuel consumption

5) Extra limitation in order to fulfill demand

6) Limitation for Assembly line Capacity

7) Demand Limitation

Table 4. Linear programming for problem (numerical example) 
Table 5. Global optimal solution found (solution by Lingo software)

\begin{tabular}{|c|c|c|}
\hline Objective value: & \multicolumn{2}{|c|}{14232.56} \\
\hline Extended solver steps & 0 & \\
\hline Total solver iterations & 4 & \\
\hline Variable & Value & Reduced Cost \\
\hline $\mathrm{X} 1$ & 0.000000 & 0.1293888 \\
\hline $\mathrm{X} 2$ & 1400.000 & 0.000000 \\
\hline X3 & 0.000000 & $0.7424180 \mathrm{E}-01$ \\
\hline $\mathrm{X} 4$ & 3600.000 & 0.000000 \\
\hline Y1 & 0.000000 & 0.1748808 \\
\hline Y2 & 10000.00 & 0.000000 \\
\hline Y3 & 0.000000 & 0.000000 \\
\hline Y4 & 0.000000 & 0.000000 \\
\hline Row & Slack or Surplus & Dual Price \\
\hline 1 & 14232.56 & 1.000000 \\
\hline 2 & 69000.00 & 0.000000 \\
\hline 3 & 7000.000 & 0.000000 \\
\hline 4 & 4600.000 & 0.000000 \\
\hline 5 & 10000.00 & 0.000000 \\
\hline 6 & 8400.000 & 0.000000 \\
\hline 7 & 10000.00 & 0.000000 \\
\hline 8 & 2000.000 & 0.000000 \\
\hline 9 & 0.000000 & 0.3575080 \\
\hline 10 & 0.000000 & 0.000000 \\
\hline 11 & 0.000000 & 0.000000 \\
\hline 12 & 0.000000 & -1.510818 \\
\hline
\end{tabular}

Appendix A): Confirmation Letter for the Results

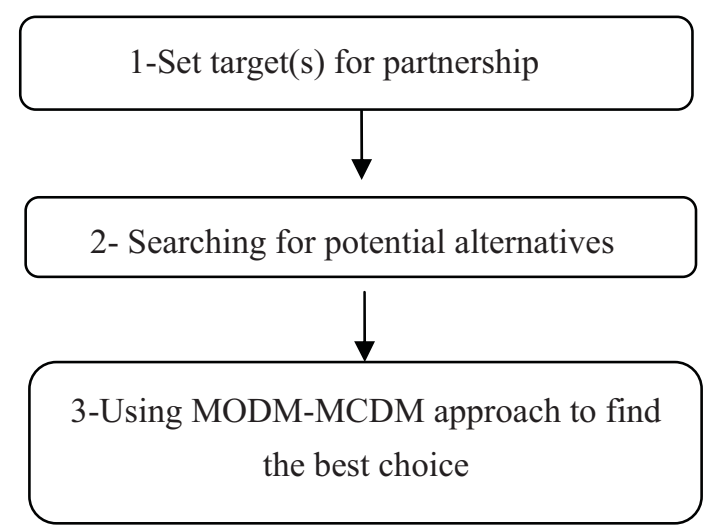

Figure 1. Model of partner selection 